\title{
Edinburgh's Hogmanay celebrations: beyond a major disaster
}

\author{
John J O’Donnell, Aidan P Gleeson, Harry Smith
}

Department of Accident and Emergency Medicine, Royal Infirmary, Lauriston Place, Edinburgh EH3 9YW J J O'Donnell A P Gleeson H Smith

Correspondence to: Dr John J O'Donnell, specialist registrar.

Accepted for publication 13 November 1997

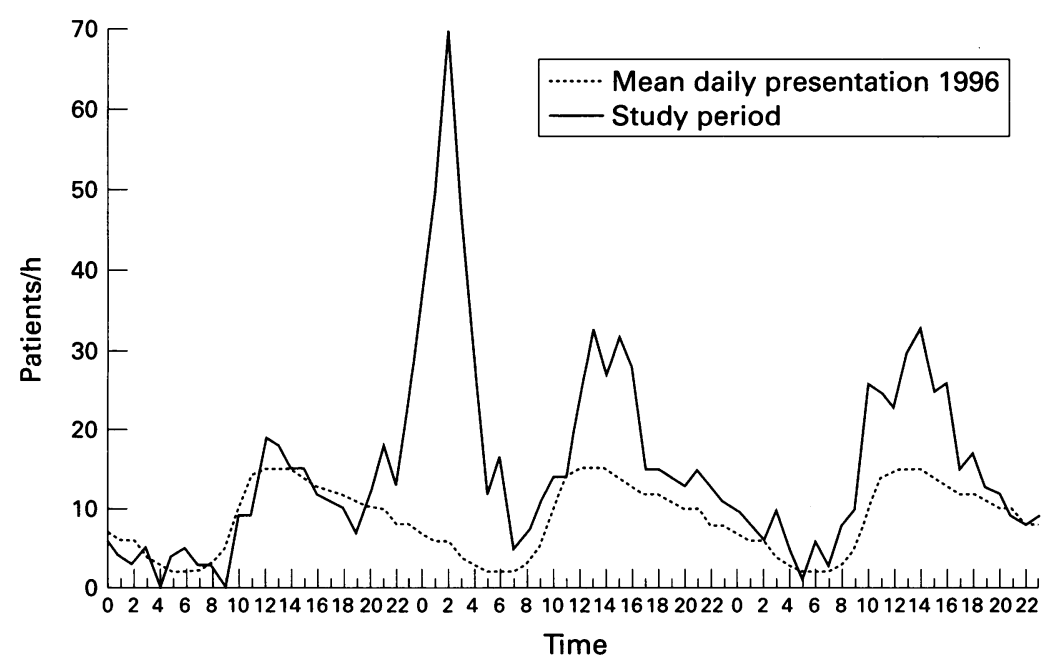

Figure 1 The hourly rate of patient presentation between 31 December 1996 and 2

fanuary 1997.

Keywords: Hogmanay celebrations; disaster planning

The scale of Edinburgh's New Year celebrations has dramatically expanded in recent years. The 1997 event was billed as "The biggest New Year's party in the world" and attracted visitors from throughout the United Kingdom and many overseas countries. The event received extensive media coverage including live television transmission nationwide. A crowd estimated at more than 350000

\begin{abstract}
Objective-To assess the impact of Edinburgh's Hogmanay celebrations on the city's accident and emergency (A\&E) service.

Methods-Retrospective analysis.

Results-A crowd estimated at more than 350000 attended the celebrations. During the three day period between $00.01 \mathrm{~h}$ on 31 December and $23.59 \mathrm{~h}$ on 2 January, 1151 new patients presented to the A\&E department and of these half arrived in the first 24 hours. Thirty six patients required emergency resuscitation and eight died in the department during the study period. Conclusions-The absolute number of patients presenting during the study period greatly exceeded most of the "major disasters" in contemporary UK experience. No deaths were directly attributable to the event, but the spectrum of patient pathologies, their severity and presentation is analogous to several recent major incidents. It is doubtful whether the Hogmanay celebrations are safe. ( 7 Accid Emerg Med 1998;15:272-273)
\end{abstract}

attended the celebrations. We describe the impact on the city's sole adult accident and emergency (A\&E) department.

\section{Results}

Between $00.01 \mathrm{~h}$ on 31 December and $23.59 \mathrm{~h}$ on 2 January, 1151 new patients presented to the A\&E department. Over half these patients arrived in the 24 hours of the 1 January, and in the first few hours the presentation rate peaked at 70 per hour (fig 1).

Overall, 781 patients were discharged home following treatment in the department. Inpatient admission was required for 332 (191 to medical wards, 61 to surgical units, 37 to orthopaedic wards, 36 to an observation ward, and seven to other specialties). Thirty patients required transfer to specialist units elsewhere. Eight patients died in the department.

Thirty six patients required emergency resuscitation. This number included eight cardiac arrests, seven patients with major injury, seven with acute respiratory failure, four with acute myocardial infarction and haemodynamic compromise, three convulsing, three with poisoning, two with subarachnoid haemorrhage, one with anaphylaxis, and one with gastrointestinal haemorrhage.

Of the cases not requiring resuscitation, 36 needed inpatient admission solely because of alcohol poisoning. Glass wounds were the presenting complaint in 43 patients, and 41 had penetrating injuries sustained from spikes on metal railings. Thirty four patients presented as a result of crushing or trampling injuries.

Radiological examinations were required for 714 patients, and 20 manipulation/reductions of fractures or dislocations were performed in the department during the study period.

\section{Discussion}

A major incident is an unexpected event requiring an extraordinary health service response. ${ }^{1}$ The absolute number of patients presenting during the study period greatly exceeds most of the "major disasters" in contemporary United Kingdom experience, ${ }^{2}$ although fortuitously no single additional incident occurred. No deaths were directly attributable to the event, but otherwise the spectrum of patient pathologies and their severity and presentation are analogous to several recent major incidents. ${ }^{2}$

In common with most hospitals, pressure on hospital beds during the Christmas and new year period is intense, and staff availability compromised. The provision of adult $A \& E$ services in Edinburgh means that the Royal Infirmary also has to cope with the routine 
workload as well as that arising from events such as this. Despite a $50 \%$ increase in A\&E medical and nursing staffing levels, the temporary use of an extra observation ward and medically manned first aid stations at the party site, the huge patient numbers created major problems for both the $\mathrm{A} \& \mathrm{E}$ department and hospital facilities.

The natural focus of the Hogmanay celebrations was midnight on 31 December, but a myriad of additional events took place over several days on either side of this. The greatest patient numbers presented between $11 \mathrm{pm}$ on New Year's Eve and 5 am on 1 January, but significant peaks occurred when patients presented later that day and again on 2 January (fig 1). This protracted nature of patient presentation led to prolonged and unremitting strain on staff and resources.

Alcohol intoxication was ubiquitous and was the single most important factor compounding the situation. Many patients and their relatives and friends were uncooperative and abusive. Difficulties were posed by even simple processes of care such as undressing patients, taking baseline recordings, $x$ ray imaging, and instituting treatment. A permanent police presence was needed in the department over the three day period to protect staff and patients against violent outbreaks.
The inherent safety of the Hogmanay celebration is questionable. This year, underfoot conditions were hazardous because of snow. Crowd barriers and railings were bent by crowd pressures and the potential for a true major incident as a result of crushing injury is ever present. Subsequent press and personal reports emphasised the "appalling, dangerous crush" and "Hillsborough all over again." 34 Major delays in transporting patients by ambulances were reported, and if life threatening injuries had occurred, access would have been difficult for ambulance and medical crews. ${ }^{5}$

Plans are proposed to increase the numbers attending to over 500000 for the millennium celebrations. At what point does encouraging people to have a good time constitute reckless irresponsibility?

We wish to acknowledge the help of Dr Colin Robertson in preparation of this paper and the extraordinary efforts of all members of staff in the accident and emergency department during the Hogmanay period.

1 Advanced Life Support Group. Major incident medical management and support manual-a practical approach. London: BMJ Publishing Group, 1995.

2 Gavalas MC, Miles SAD. Hospital response to disasters in Gavalas MC, Miles SAD. Hospital response to disasters in
the UK. In: Skinner D. Swain A, Peyton R, Robertson C, eds. Cambridge textbook of accident $\mathcal{E}$ emergency medicine. Cambridge: Cambridge University Press, 1997.

3 Wells M. Reveller's report. The Scotsman 1997 January 3.

4 Notarelangelo R. Cops launch probe into Hogmanay crush hell. The Daily Record 1997 January 3.

5 Thorpe N. Ambulance chief joins call for party review. The Scotsman 1997 January 4

\title{
Notice of Conference Emergency Medicine \& Pre-hospital Care
}

\author{
Johannesburg, South Africa \\ 7-9 October 1998
}

For further details, contact:

The Registrar, Emergency Medicine \& Pre-hospital Care Conference, Strategic Business Services (Pty) Ltd, PO Box 1059, Oakdale 7534, South Africa. Fax: +27 (0)21 9142890 ; e-mail: registrar@sbs.co.za 